\title{
Solublization Effect on Nano-h-BN Performance in New Lubricant Generation
}

\author{
Aleksandra Mrela ${ }^{1}$, Zenon Pawlak ${ }^{2 *}$ and Wieslaw Urbaniak ${ }^{3}$ \\ ${ }^{1}$ Kujawy and Pomorze University in Bydgoszcz, Faculty of Technology, Europe \\ ${ }^{2}$ Tribochemistry Consulting, University of Economy, Europe \\ ${ }^{3}$ Kazimierz Wielki University, Faculty of Mathematics, Physics and Technical Sciences, Europe
}

Received: 非 June 19, 2018; Published: 彗July 06, 2018

*Corresponding author: Zenon Pawlak, Tribochemistry Consulting, Salt Lake City, UT 84117, USA, University of Economy, Biotribology Laboratory, Garbary 2, 85-229 Bydgoszcz, Poland, Europe

\begin{abstract}
h-BN nanoparticles when added to hydrocarbona base oil alone exhibit low friction and low wear-reducing abilities. In automotive oil the dispersantis one of the additives and participates in solubilization of h-BN nano-particles. Also, solubilization will reduce adhesion of h-BN particles on the steel surfaces. Low dispersant concentrations under control are required for a new generation of automotive oils.

Keywords: Solublization Effect; New Lubricant Generation; Nano-h-BN; Low Dispersant; Nanoparticles; Lamellar Structure; Automotive Lubricant; Amonton's law; Exfoliate; Surface Temperature
\end{abstract}

\section{Introduction}

Some nano-particles especially with lamellar structure (h-BN, $\mathrm{WS}_{2}, \mathrm{MoS}_{2}$ ) added to base oil have shown very good lubrication properties especially low friction [1,2]. Nanoparticles have a tendency to agglomerate and should be dispersed in presence of dispersant. In automotive lubricant dispersant is always present as additive. When nano-h-BN is added to commercial oil we can expect dispersion h-BN particles with involvement of reverse micelles formed by surfactants and such process is named solubilization. Micellar solubilization is the process of incorporating the h-BN particles into core of micelles. Solubilization process can be called deactivation of h-BN lubricant particles. In severe boundary lubrication condition [3] and under high contact pressures micelles with the solubilizate nano-h-BN nanoparticles have been shown to exfoliate in the contact, leading to the release of additive h-BN [3] (Figure 1). These h-BN platelets then adhere to the steel surface, resulting into thin layers formation. To design automotive new generation oil based on nanoparticles additives some technical issues should be resolved:

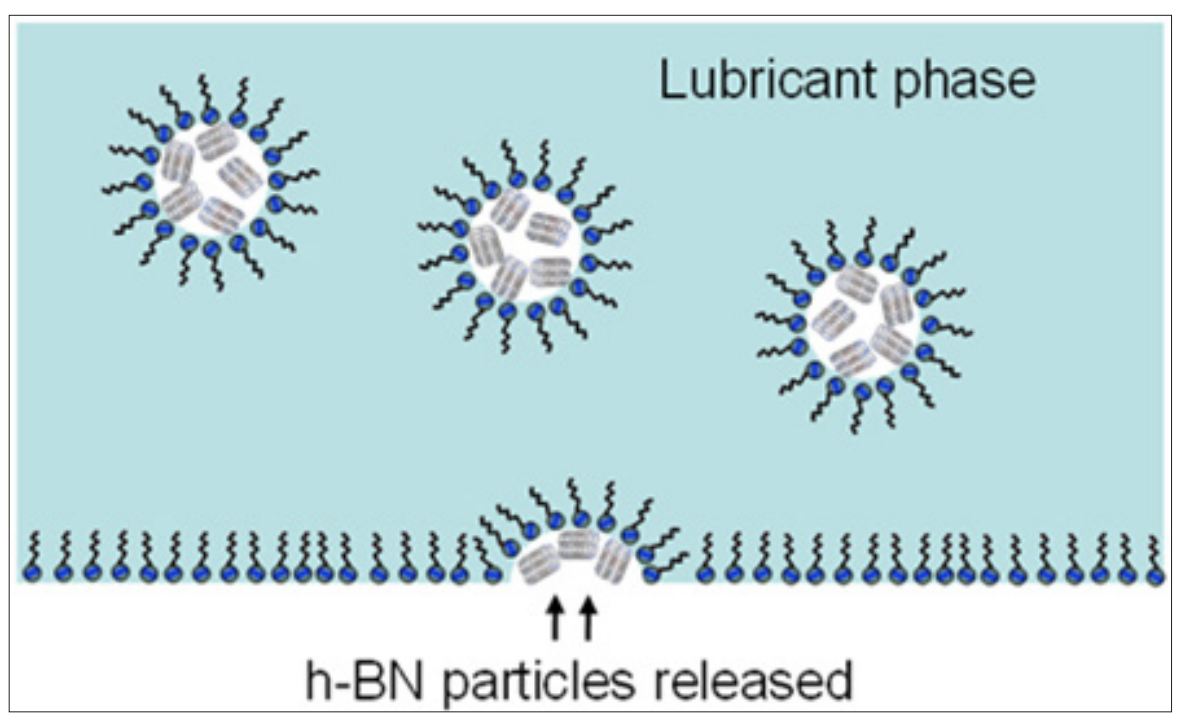

Figure 1: Solubilization of h-BN particles in formulated oil Selectol with surfactant molecules on h-BN Particles released from surface porous sinter (iron $+\mathrm{h}-\mathrm{BN}$ ) bearing during the wear process in automotive lubricant [2]. 
a) Concentration of nano-additive and surfactant

b) A proper dispersion and stability of the nanoparticles

c) Proper evaluation friction and wear parameter.

In this work we study two lubricants

a) Formulated oil Selector contained surfactant with h-BN and Hydrorafinat

b) Tribological pair: porous sinter (iron + h-BN)/grey cast irondisc in hydrocarbon oil without surfactant.

\section{Materials and Methods}

Frictional measurements were carried out using a KEWAT-6 multifunctional friction machine designed to study friction of porous sintered samples under varying temperatures. A simplified scheme of the KEWAT-6 station is presented in [2]. Frictional pairs: Sample of porous non-full journal bearing / counter balance sample (grey cast iron drum (Ø) $100 \mathrm{~mm}$, the H235 hardness class) [2]. The frictional forces during the test were measured until reaching the threshold surface temperature $(\mathrm{Te})$ of $150^{\circ} \mathrm{C}$. The results were used to calculate the friction coefficients using Amonton's law, $\mathrm{T}=\mathrm{f} \mathrm{N}$; where: $\mathrm{T}$ - the friction force, $\mathrm{f}$ - the dimensionless quantity called the friction coefficient, $\mathrm{N}$ - load or normal force.

\section{Results and discussion}

In this research the influence of surfactant on h-BH particles released in the contact porous sinter (iron $+\mathrm{h}-\mathrm{BN}$ )/grey cast irondisc were studied. The h-BN released particles were carefully compared for solubilization when using

a) Formulated oil Selector with surfactant and

b) Surfactant-free hydrocarbon oil Hydrorafinat. The h-BN particles were shown to produce a considerable reduction in friction when using only the hydrocarbon base oil. The sintered porous bearings (iron $+\mathrm{h}$-BN) $(0,5,10,20,30$ and $50 \mathrm{wt}$. \% h-BN) impregnated with oil showed an unresolved friction reduction in the oil-free surfactant. A relation between the h-BN content in porous sinter and friction coefficient was evaluated. The effect of surfactant on the lubrication by the h-BN particles was discussed relative to the solubilization process.

A) Presence of h-BN in the porous sintered bearings and consequences for frictional properties

The data collected during the friction test with varying h-BN concentrations and temperature of up to $150^{\circ}$ Care plotted in Figure 2 for Hydrorafinat and Selectol oils. Considering the Hydrorafinat mineral oil, the lowest (f) value of 0.05 was obtained from the porous sinter, and is similar to that obtained for the iron $+20 \%$ h-BN.The increased content of h-BN in the porous sinterfor iron + $30 \mathrm{wt}$. \% h-BN was found to be "beneficial" for lamellar platelets of all the Selectol lubricant with reducing friction coefficient (f) $<0.2$ after about 1,000 seconds. The transfer of the solid particles from one contact surface to another is believed to be the main feature of the mechanism of reducing the friction with solid lubricant particles.

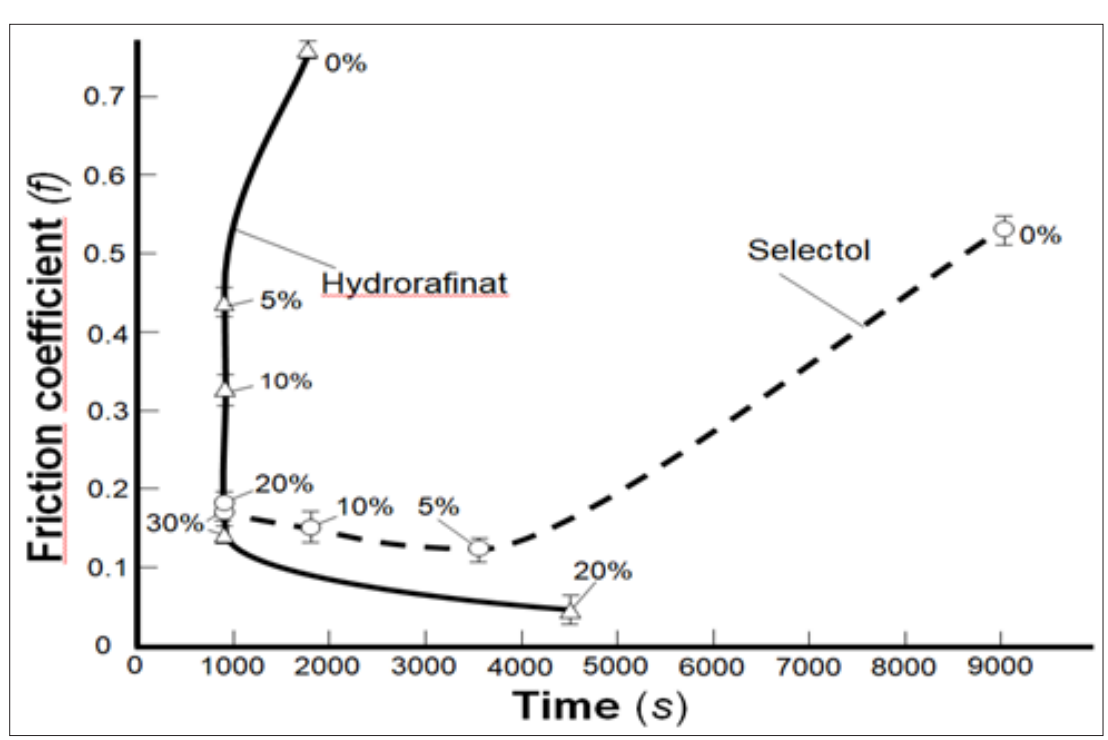

Figure 2: Plot of the friction coefficient vs time for porous sintered bearings (iron $+\mathrm{h}-\mathrm{BN}$ ) with various concentration of $\mathrm{h}-\mathrm{BN}(0,5,10,20$, and $30 \mathrm{wt} \%)$ of $27.8 \%$ porosity impregnated with pure hydrocarbon Hydrorafinat (without surfactant)and formulated oil (surfactant present) Selectol engine oil at $150^{\circ} \mathrm{C}$ Values of friction points taken after surface reached.

\section{Conclusion}

The h-BN particles in a surfactant-free hydrocarbon oil and in formulated oils showed large differences. In the hydrocarbon Hydrorafinat oil, the h-BN particles provide an active lamellar lubricant through avoiding deactivation by the surfactant. The surfactant present in the formulated oil was found to be at least partly responsible for the reduced effectiveness of the h-BN particles. Finding the balance between surfactant content and percentage of the h-BN particles has been our aim with the potential to develop a new generation of oils. Friction tests revealed that the average value of coefficient of friction was by 15 times lower for Hydro 
rafinat, $\sim 4$ times lower for Selectol oil as compared to the reference samples with $(0.0 \mathrm{wt} . \% \mathrm{~h}-\mathrm{BN})$ in the porous sinter. A lubricant based on impregnated powdered materials could be presented as a mixture of oil and wear particles to produce an effective product.

\section{Acknowledgments}

Podniesienie gotowosci wdrozeniowej -"Inkubator i nowacyjnosci plus" G. nr 07/01/2017-UKW

\section{References}

1. L Rapoport, L Lvovsky, M Lapsker, I Leshinsky, W Volovik et al. (2001) Friction and wear of bronze powder composites including fullerene-like $\mathrm{WS}_{2}$ nanoparticles. Wear 249(1-2): 150-157.

\section{ISSN: 2574-1241}

DOI: 10.26717/BJSTR.2018.06.001361

Zenon Pawlak. Biomed J Sci \& Tech Res

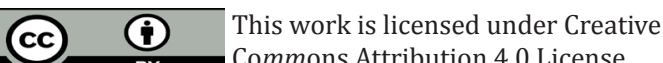

Submission Link: https://biomedres.us/submit-manuscript.php
2. Pawlak Z, Kaldonski TJ, Macko M, Urbaniak W (2017) h-BN lamellar lubricant in hydrocarbon and formulated oil in porous sintered bearings (iron+h-BN). Archives of Civil and Mechanical Engineering 17(3): 687693.

3. Rabaso P, Dassenoy F, Ville F, Diaby M, Vacher B et al. (2014) An investigation on the reduced ability of IF-MoS2 nano particles to reduce friction and wear in the presence of dispersants. Tribol Letters 55(3): 503-516.

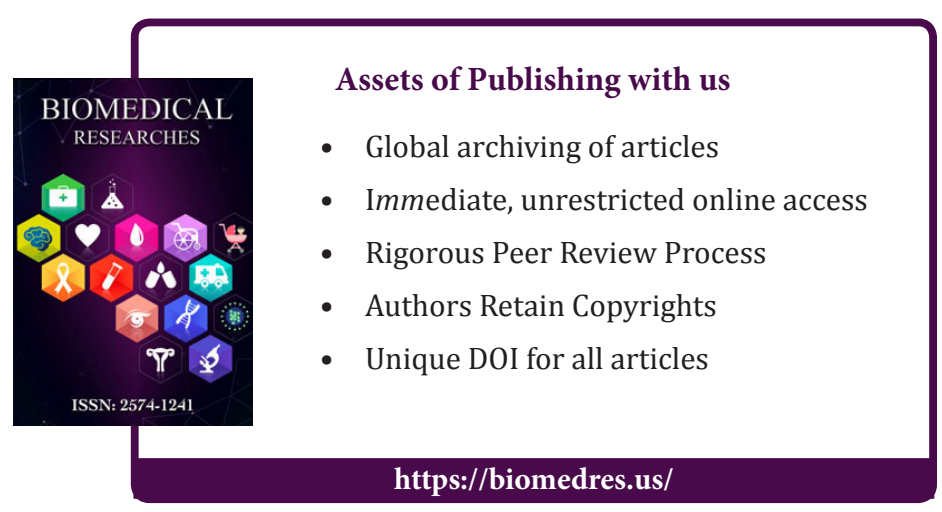

